\title{
En mann i 80-årene med gjentatte synkoper
}

\author{
Besvimelse - synkope - rammer inntil halvparten av oss i løpet av livet \\ og er årsak til et høyt antall innleggelser i sykehus. For langt de fleste \\ er synkope et ufarlig fenomen, men når er det farlig og må utredes? \\ Gjennom denne kasuistikken forsøker vi å belyse dette.
}

Pasienten, en mann i midten av 80-årene, ble henvist fra fastlegen til privatpraktiserende kardiolog med spørsmål om kardial årsak til synkope. I henvisningen var det beskrevet to tilfeller av mulig bevissthetstap de to foregående ukene. Det var ikke registrert følgesymptomer som hjertebank, angina, pustebesvær, kvalme eller oppkast.

Ved utredning av synkope er det først viktig å stadfeste at det virkelig er dette. Epileptiske anfall, vertigo, panikkanfall og fall er ikke synkoper og skal ikke utredes som det. Dette kan ofte avklares gjennom anamnesen, eventuelt med støtte fra komparentopplysninger. Dersom det foreligger et akutt inntruffet, kortvarig bevissthetstap med tap av postural tonus og med spontan, rask og total helbredelse, er synkopediagnosen sannsynlig (1).

Det ble i henvisningen videre beskrevet at det var usikkert om pasienten hadde hatt komplette bevissthetstap, men det ble slått fast at han hadde falt om og vært ute av stand til å bevege seg eller snakke. Han hadde opplevd dette også tidligere, men det kom ikke frem hvorvidt han var utredet for det. Begge de beskrevne tilfellene hadde inntruffet mens han var oppreist og i bevegelse.

Ved undersøkelse hos fastlegen ble det ikke funnet nevrologiske utfall, og EKGundersøkelse viste sinusrytme uten iskemitegn. Blodtrykket var $156 / 77 \mathrm{~mm} \mathrm{Hg}$, pulsen 67/min. Fastlegen mistenkte ifølge henvisningen primært en nevrologisk hendelse og henviste til ultralyd av halskar. Samtidig ble det henvist til kardiolog for utredning av «ev. kardial årsak til plagene».

Ved synkope er patogenesen for bevissthetstapet forbigående global cerebral hypoperfusjon (1). De viktigste differensialdiagnosene er epileptisk anfall, traumatisk bevissthetstap, pseudosynkope (psykogent anfall) og kortvarig bevissthetstap av annen årsak (1). Transitorisk iskemisk anfall (TIA) er nesten aldri en differensialdiagnose ved synkope, da det definisjonsmessig vil gi fokalnevrologiske utfall (om enn forbigående) og - viktigst her - svært sjelden vil forårsake bevissthetstap (1).
Dessverre er det en vanlig misoppfatning at TIA ofte forårsaker synkope. Det gjør at mange pasienter med disse diagnosene feilaktig henvises til primær utredning hos nevrolog med det som viser seg å være synkope, eller til kardiolog med det som viser seg å være TIA. Det kan medføre unødvendige og kostbare undersøkelser som CT caput, EEG eller ekkokardiografi, og i verste fall en kompliserende forsinkelse i diagnostiseringen.

Pasienten var til vanlig oppegående med rullator. Han hadde hatt et hjerteinfarkt om lag 25 år tidligere, hadde tablettregulert diabetes og hypertensjon og var operert for perifer aterosklerotisk sykdom $i$ en underekstremitet. Han brukte et kombinasjonspreparat med ACE-hemmer (enalapril) og tiazid, et peroralt antidiabetikum og en blodplatehemmer (dipyridamol) i ukjent dose. Dessuten brukte han snus.

Synkope klassifiseres i dag i tre hovedgrupper, avhengig av underliggende mekanisme: reflekssynkope, ortostatisk synkope og kardial synkope (1). Det er viktig å gjøre seg opp en mening om mekanismen hos den enkelte pasient, da dette er vesentlig for risikovurderingen og behovet for videre utredning.

Hvis det ikke har vært fullt bevissthetstap, er det definisjonsmessig ikke synkope. Når pasienten har opplevd prodromalsymptomer og hatt følelsen av å skulle besvime, uten at bevissthetstap har inntruffet, beskrives det som presynkope eller nærsynkope (1). Vanligvis vil man ikke begynne synkopeutredning ved nærsynkope. Hos denne pasienten var det noe usikkert om det hadde vært totalt tap av bevissthet og postural tonus. Likevel valgte man å utrede for denne verstefallsmuligheten, sannsynligvis fordi han hadde mange risikofaktorer for kardial synkope (som tidligere hjerteinfarkt, hypertensjon og diabetes).

Pasienten møtte ikke til første oppsatte time, han kom til kardiolog først tre måneder etter henvisningstidspunktet. Det ble tatt standard 12-avlednings-EKG, som viste sinusrytme med frekvens $76 / \mathrm{min}$. Patologiske $Q$-takker i nedre vegg viste gjennomgått infarkt, noe som også forklarte det lett

\author{
Sigurd Haakonsen \\ Medisinsk fakultet \\ Universitetet i Oslo \\ Per Anton Sirnes \\ $\emptyset$ stlandske hjertesenter \\ Moss \\ Knut Gjesdal \\ knut.gjesdal@medisin.uio.no \\ Kardiologisk avdeling \\ Oslo universitetssykehus, Ullevål \\ > Se kommentar side 56
}


breddeforøkte QRS med venstre aksedeviasjon. Det var i tillegg ST-avvik fra grunnlinjen og T-bølgeinversjon som passet med gammelt infarkt (fig 1).

Blodtrykket målt liggende var $115 / 66 \mathrm{~mm}$ Hg. Pasienten ble påkoblet en 24-timersEKG-opptaker med to kanaler for å avdekke eventuell arytmi og sendt hjem med avtale om ny konsultasjon påfølgende dag med utdypende anamnese, avlesning av 24-timersEKG og ekkokardiografi.

Hos pasienter med synkope bør det alltid tas EKG-undersøkelse (1). Det kan avdekke eventuelle tidligere hjerteinfarkt og om det er ledningsforstyrrelser eller andre kardiale patologiske forhold. Også hos yngre er EKGundersøkelse viktig for ikke å overse sjeldne, men farlige tilstander som ionekanalsykdommer (f.eks. langt QT-syndrom) og kardiomyopatier (f.eks. hypertrofisk kardiomyopati og arytmogen høyre ventrikkelkardiomyopati). Hvis pasienten sjelden har symptomer, og spesielt hvis det er mistanke om vasovagal mekanisme, bør man avstå fra langtids-EKG-opptak (24-72 t), da verdien $i$ en slik situasjon er lav $(1,2)$. Ved hyppige symptomer derimot, er langtids-EKG-opptak ofte diagnostiske, både positivt ved påvisning av symptomrelaterte arytmier og negativt hvis pasienten synkoperer uten å ha arytmi (1).

Ved mistanke om kardial årsak til synkopen skal pasienten utredes for hjertesykdom, inkludert arytmier. Da bør også langtids-EKG tas, selv ved sjeldne symptomer. I den forbindelse er det ikke sjelden at funn av eksempelvis sinusknutesvikt, intermitterende atrioventrikulært blokk, korte løp med ventrikkeltakykardi eller atrieflimmer kan være nyttig for å stille en diagnose. Eventuelt kan det i slike tilfeller være hensiktsmessig med bruk av hendelsesstyrte EKGopptakere (2). Avhengig av pasienthistorie og mistenkt etiologi kan man bruke enten eksterne opptakere, som pasienten gjerne tolererer å gå med i 1-2 uker, eller implanterbare opptakere med en batterilevetid på inntil tre år. Felles for disse er at de ikke kan ta vare på opptaket for hele perioden, men at de lagrer EKG etter forhåndsinnstilte kriterier eller ved aktivering av pasienten ved symptomer (loop-recorders).

Dersom det foreligger en eller flere risikofaktorer for kardial synkope, og særlig dersom synkopeepisoden nettopp har inntruffet, bør den initiale rytmeovervåkingen skje i sykehus, hvor man kan behandle eventuelle arytmier (1).

Dagen etter at han fikk påmontert EKG-opptaker, mens denne fortsatt registrerte, døde pasienten hjemme. Ifølge komparentopplysninger hadde han kjent seg uvel og hadde lagt seg. Litt senere ble han bevisstløs - og noen minutter senere døde han.

EKG-opptaket pågikk i mer enn 21 timer og ble $i$ ettertid analysert med tanke på iskemi (ST-avvik) og frekvenskorrigert QT-tid (QTC). Analysen viste ST-senkning på $0,1 \mathrm{mV}$ de første timene, økende til ca. 0,25 mV gjennom siste halvdel av perioden. Deretter ses omslag til atrieflimmer med ventrikkelfrekvens på over 160/min tidlig om morgenen og en ytterligere ST-senkning. Etter få minutter med atrieflimmer slår rytmen om til en monomorf ventrikkeltakykardi, for så etter ett minutt å gå over til ventrikkelflimmer og etter hvert hjertestans. De viktigste hendelsene er vist $i$ figur 2.

\section{Diskusjon}

Synkope defineres av European Society of Cardiology som et forbigående bevissthetstap som skyldes forbigående global cerebral hypoperfusjon og kjennetegnes ved å være akutt inntreffende og av kort varighet, fulgt av spontan og komplett helbredelse (1). Årsaken til synkope er nesten alltid fall i det systemiske blodtrykket. Et systemisk middelarterietrykk på under $60 \mathrm{~mm} \mathrm{Hg}$ er lavt nok til å forårsake synkope hos en stående voksen person (1). Det samme er opphevet cerebral sirkulasjon i 6-8 sekunder, for eksempel ved asystoli (1). Den fysiologiske reguleringen av blodtrykket gir grunnlag for en tredeling av mekanismene bak synkope, som gjengitt i figur 3 (1).

Reflekssynkope, ofte omtalt som vasovagal synkope (selv om dette strengt tatt kun er en undergruppe av reflekssynkopene), er den dominerende. Den skyldes et abrupt opphør i mekanismer som normalt opprettholder blodtrykket. Kroppens forsøk på å motvirke blodtrykksfallet via det autonome nervesystemet medfører ofte (men ikke alltid!) typiske autonome prodromalsympto-

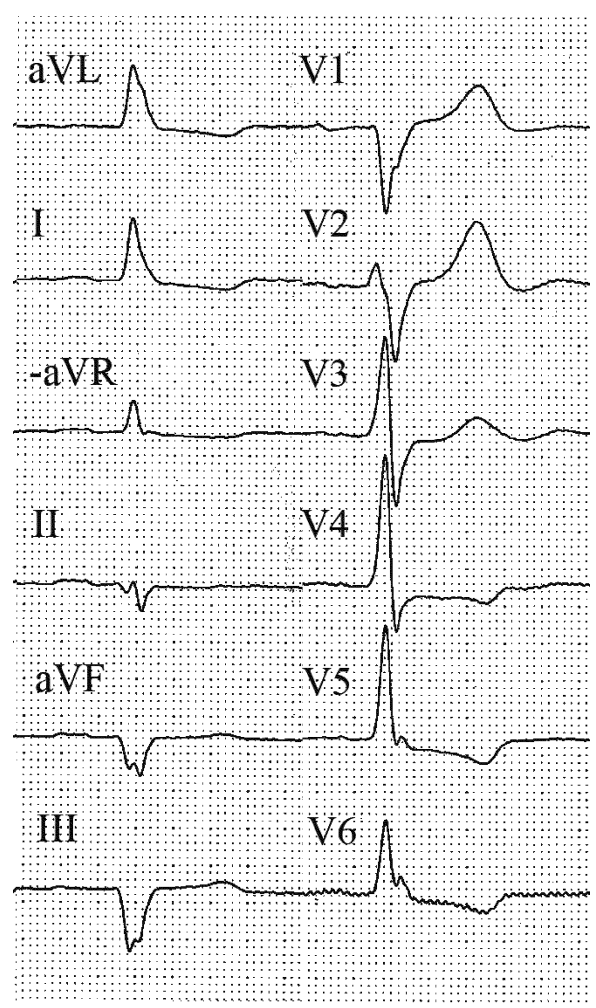

Figur 1 Pasientens EKG ved undersøkelse hos kardiolog. $50 \mathrm{~mm} / \mathrm{s}$. Det ses sinusrytme med patologiske Q-takker i nedre vegg, lett breddeforøket QRS samt ST-avvik og T-inversjoner svarende til gjennomgått infarkt. Målte verdier (normalverdier): $P Q$-tid 0,20 s $(<0,22 \mathrm{~s}), \mathrm{QRS}$-tid 0,12s(<0,12 s) og QTC 0,41s (<0,47s (menn) og <0,48s (kvinner)). Eventuelle funn av pauser på > $3 \mathrm{~s}$ burde $i$ en slik situasjon initiere videre utredning

mer som svette, blekhet, kvalme og svimmelhet. Hos unge er dette den dominerende form (1). Vasovagal synkope er som regel ufarlig, men kan være svært belastende for den tredelen av pasientene som opplever flere episoder (1).

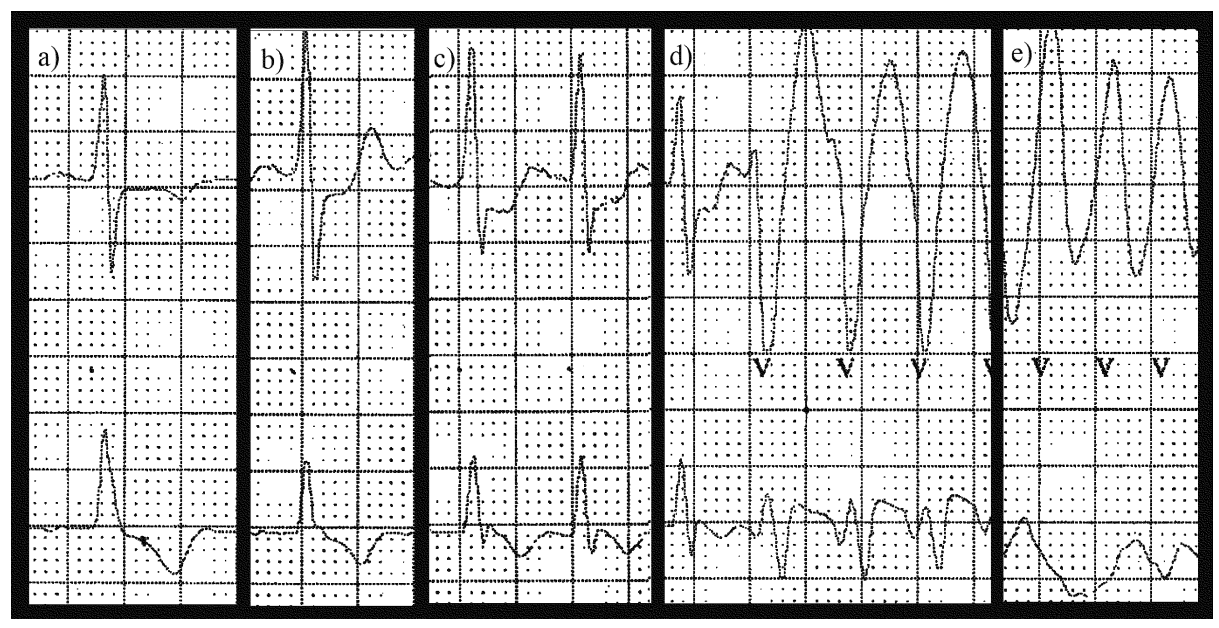

Figur 2 Detaljer fra 24-timers-EKG. 25 mm/s. al Sinusrytme tidlig i opptaket. bl Sinusrytme like før omslag til c) atrieflimmer. d) Omslag ventrikkeltakykardi. e) Ventrikkelflimmer 


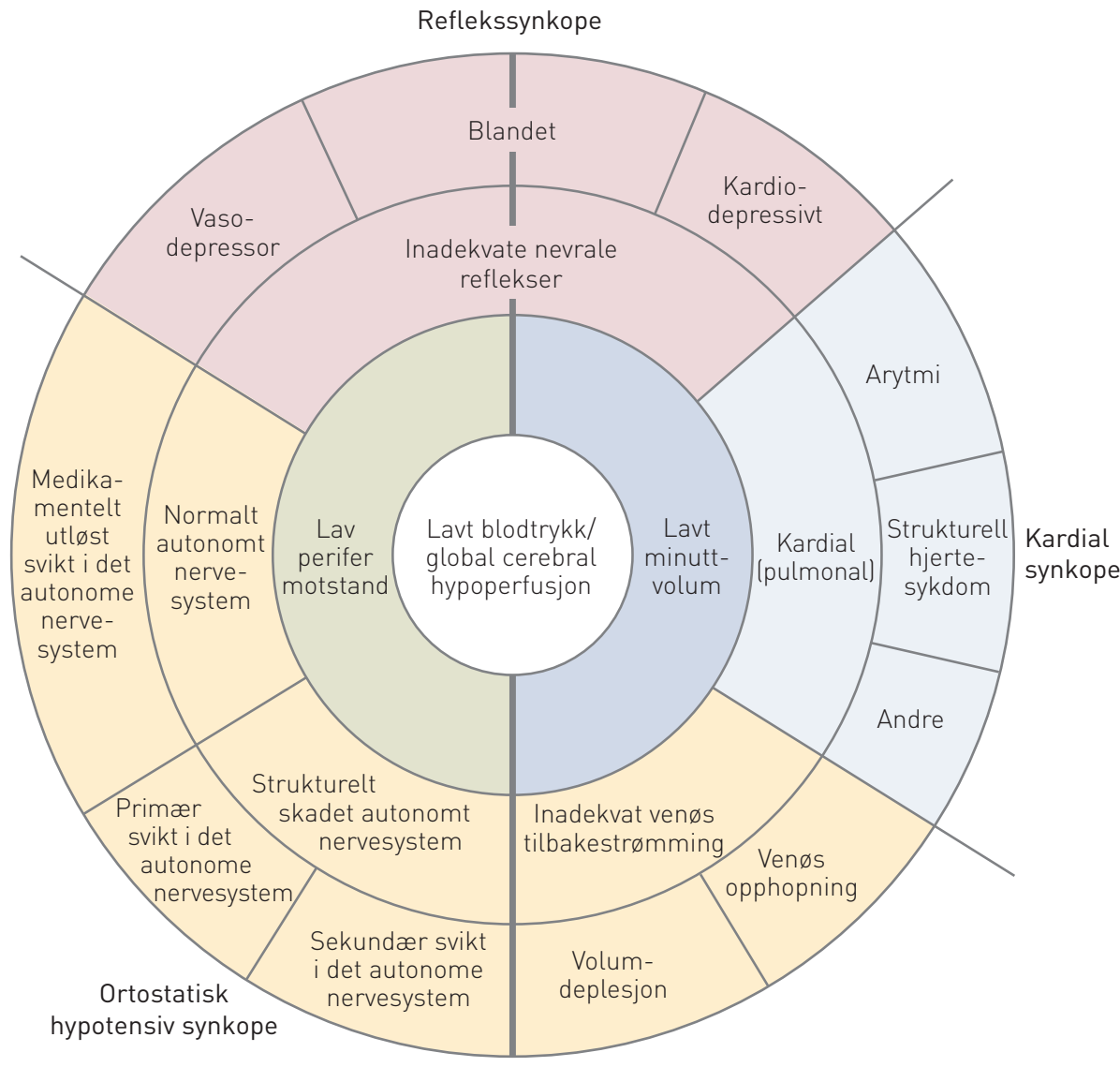

Figur 3 Oversikt over patofysiologien ved kardiale sykoper, ortostatiske synkoper og reflekssynkoper (1). Gjengitt med tillatelse

Den andre gruppen, ortostatisk hypotensiv synkope, er sjelden hos unge mennesker. Forekomsten øker med alderen. Ortostatisk hypotensiv synkope ses særlig hos middelaldrende og eldre som får antihypertensiv behandling og hos mennesker med diabetes eller andre med risiko for autonom dysfunksjon (3). Diagnosen er som regel lett å stille - et fall på $20 \mathrm{~mm} \mathrm{Hg}$ i systolisk blodtrykk og/eller $10 \mathrm{~mm} \mathrm{Hg}$ diastolisk målt etter tre minutter ved endring av stilling fra liggende eller sittende til stående er den aksepterte definisjonen på ortostatisk hypotensjon (1, 3 ). For at diagnosen ortostatisk hypotensiv synkope skal kunne stilles, kreves samtidig bevissthetstap. Ortostatisme er for øvrig også en uavhengig risikofaktor for kardiovaskulær sykdom og død (3).

Kardiale synkoper er den tredje gruppen og omfatter tilfeller der hjertets pumpefunksjon er kompromittert. Dette kan skje ved arytmier (både taky- og bradyarytmier) og ved strukturell sykdom som svekker hjertets pumpeevne eller øker dets pumpemotstand. Eksempler på bradyarytmier er syk sinus-syndrom og atrioventrikulært blokk, eksempler på takyarytmier er supraventrikulære takykardier, atrieflimmer og ventrikkeltakykardi. Felles for de takykardiutløste synkopene er at de ofte inn- treffer rett etter omslag til arytmi, før reduksjonen i minuttvolum er kompensert (1).

Strukturell sykdom som kan ligge bak en kardial synkope, er blant annet aortastenose, hjertesvikt og koronar iskemi. Mistanken om kardial synkope øker når besvimelsen inntreffer i liggende eller sittende stilling, under fysisk anstrengelse, ved kjent hjerte- og karsykdom eller annen alvorlig komorbiditet og der det er tilfeller av plutselig død eller kjent kanalopati i nær slekt (1). Nyoppståtte palpitasjoner umiddelbart før synkope eller et unormalt EKG er også varselstegn (1).

Forekomsten av de tre hovedgruppene for synkope vil avhenge av populasjonen som undersøkes. I normalpopulasjonen regner man med at minst $21 \%$ hører til reflekssynkopene, ortostatisk hypotensiv og kardial synkope teller ca. $10 \%$ hver, mens en stor andel forblir uforklart (1). Undersøkelser fra spesialisthelsetjenesten viser ofte langt høyere andel reflekssynkope, $\mathrm{i}$ hovedsak på bekostning av de uforklarte, men det er store variasjoner (1).

Synkope er, med unntak av eventuelle skader som følge av fall, sjelden ansett som farlig per se (1). Risikoen for død etter synkope er lav, men den er likevel signifikant høyere hos de rammede enn i normalpopulasjonen $(1,4)$. Dette skyldes nok at synkope fremkommer som symptom på underliggende sykdom heller enn at det i seg selv er årsak til død (1).

I en nylig publisert metaanalyse fra D' Ascenzo og medarbeidere, med mer enn 43000 pasienter med synkope evaluert i akuttmottak, var dødeligheten 4,4\% etter en median oppfølgingstid på én måned (4). En firedel av disse dødsfallene hadde en antatt kardiovaskulær årsak, mens noen flere var uforklarte. Derose og medarbeidere gjennomgikk over 22000 pasienthistorier og fant en total 30 -dagersdødelighet på $1,4 \%$, med en høyere andel kardiovaskulære dødsfall $(35 \%)$ enn det D'Ascenzo og medarbeidere fant (5). Studiene indikerer at de kardiale synkopene ofte er symptom på alvorlig underliggende hjertesykdom. Ettårsdødeligheten etter kardial synkope er beregnet å ligge på mellom $18 \%$ og $33 \%$ (2).

Viktig å merke seg er at synkope for pasienten kan medføre midlertidig forbud mot å kjøre bil og for legen meldeplikt til Fylkesmannen (ramme 1) $(6,7)$.

ESC-retningslinjene anbefaler følgende standardutredning ved synkope når det ikke er en åpenbar reflekstype: grundig anamnese, klinisk undersøkelse inkludert måling av ortostatisk blodtrykk og standard 12avlednings-EKG, helst også med carotismassasje i tillegg til EKG hos dem over 40 år (sjekk at det ikke er stenoselyd!) (1). Dersom dette ikke gir diagnosen, bør videre utredning skje hos spesialist i hjertesykdommer eller på sykehuspoliklinikk.

Noen poliklinikker har en egen enhet for synkopeutredning med rytmediagnostikk og spesialundersøkelser som vippetest og mulighet for nevrologisk tilsyn der det er tvil om diagnosen. For allmennlegen vil identifisering av pasienter med kardial synkope være det viktigste - da skal pasientene hastehenvises videre, enten som øyeblikkelig hjelp til innleggelse eller til rask utredning ved poliklinikk eller hos spesialist (1). Kjent alvorlig strukturell hjertesykdom, klinisk eller elektrokardiografisk mistanke om arytmi som årsak til synkope eller alvorlig komorbiditet som anemi eller elektrolyttforstyrrelser er alle indikatorer for kardial synkope (1). Ulike algoritmer for en kostnadseffektiv og målrettet utredning av synkope er foreløpig ikke godt validert (8).

Hva så med vår pasient? I ettertid har vi fått opplysninger om at han hadde hatt flere episoder med plutselig innsettende fullt bevissthetstap. Det dreide seg dermed om gjentatte synkoper som oppsto under bevegelse hos en blodtrykksbehandlet eldre pasient med diabetes og tidligere hjerteinfarkt. Basert på disse forutsetningene er vasovagal mekanisme lite sannsynlig. Ortostatisk blodtrykksfall var også mindre sannsynlig, blant annet fordi det oftere skjer når man står stille 


\section{RAMME 1}

\section{Synkope og førerkort (for person-/varebil)}

Etter et anfall med bevissthetstap, så som synkope, er førerkortforskriftens helsekrav ikke oppfylt i 12 måneder (6). Legen har skriftlig meldeplikt til pasienten og Fylkesmannen. Helsedirektoratets veiledning utdyper bestemmelsen (7). Anfall som er åpenbart irrelevante for trafikksikkerheten faller utenfor. Vurderingen av dette kan være vanskelig og blir lett farget av pasientens behov for førerkort og lege-pasientforholdet.

Banal, enkeltstående, noenlunde sikker vasovagal synkope, miksjonssynkope og synkope under medisinske prosedyrer er eksempler på synkoper som er irrelevante for trafikksikkerheten. Gjentatte, brått innsettende synkoper, synkoper i sittende eller liggende stilling og synkope med skade er derimot nesten alltid trafikksikkerhetsmessig relevante. Mistenkt kardial synkope er trafikksikkerhetsmessig relevant pga. residivrisiko og alvorlig prognose.

Viktigste prediktorer for residivrisiko etter uforklart synkope er antall tidligere synkoper og tid fra siste synkope. Dersom pasienten ønsker å kjøre før karenstiden på 12 måneder er gått, kan Fylkesmannen gi dispensasjon dersom årsaken er klarlagt og eliminert eller er av en slik art at residiv er usannsynlig. Pasienten søker selv. Legen gir attest med resymé av de faktiske forhold og en faglig vurdering av trafikkrelevans og residivrisiko.

enn når muskelpumpen $\mathrm{i}$ beina er $\mathrm{i}$ bruk. En ortostatisk blodtrykksmåling ble dessverre ikke gjort på fastlegekontoret eller hos hjertespesialisten. Den er enkel å utføre, og ville, dersom negativ, ha styrket mistanken om kardial synkope.

Den rimelige tolkingen av EKG-utskriften er at pasienten utviklet iskemiutløst atrieflimmer. Rask overledning til ventriklene kan ha forverret iskemien, og arytmien degenererte til ventrikkeltakykardi og deretter til ventrikkelflimmer, som ledet til dødsfallet. Episodene som ble beskrevet $\mathrm{i}$ henvisningen, kan etter vår vurdering ha vært anfall med atrieflimmer med rask ventrikkelfrekvens eller ikke-vedvarende ventrikkeltakykardi, som har gitt forbigående hypotensjon.

Ved mistanke om synkope med bakgrunn i underliggende hjertesykdom er rask utredning hos spesialist av stor betydning. Ved mistanke om kardial synkope bør pasienten bli innlagt for videre utredning eller hastehenvist til utredning i poliklinikk eller hos privatpraktiserende spesialist. I utgangspunktet betyr hastehenvisning time neste dag, men samtidig avhenger hastegrad, etter vår vurdering, av hvor lenge det er siden synkopeepisoden.

Differensialdiagnostikken for å skille mellom TIA og synkope er som regel grei, og problemstillingen kardial synkope i henvisningen bør føre til raskere time hos kardiolog. Erkjennelse av atrieflimmer som årsak til synkope kunne initiert oppstart av frekvensregulerende behandling, for eksempel en betablokker, som bremser overledningen i AV-knuten og reduserer risikoen for overgang til ventrikkeltakykardi (9).

For denne pasienten, som var gammel, redusert og plaget med betydelig komorbiditet, kan det naturligvis diskuteres hvorvidt utfallet kunne blitt vesentlig endret og om spesialisthenvisning derfor var påkrevd.

Pasientens pårørende har gitt samtykke til at artikkelen blir publisert.

Vi takker overlege dr.med. Torkel Steen, som har utformet teksten i ramme 1 om reglene for førerkort

\section{Sigurd Haakonsen (f. 1983)}

er medisinstudent. Artikkelen er hans obligatoriske prosjektoppgave. Han har bidratt med utforming, analyse av data, litteraturs $\varnothing k$, utarbeiding og revisjon av manuskriptet og godkjenning av innsendte manuskript. Forfatter har fylt ut ICMJE-skjemaet og oppgir ingen interessekonflikter.

\section{Per Anton Sirnes (f. 1954)}

er dr.med., spesialist hjertesykdommer og avtalespesialist i Moss. Han har bidratt med idé, datainnsamling, utarbeiding og revisjon av manuskriptet og godkjenning av innsendte manuskript.

Forfatter har fylt ut ICMJE-skjemaet og oppgir ingen interessekonflikter.

\section{Knut Gjesdal (f. 1944)}

er professor i hjertesykdommer og overlege. Han har bidratt med idé, utforming, tolking av data, utarbeiding og revisjon av manuskriptet og godkjenning av innsendte manuskript. Forfatter har fylt ut ICMJE-skjemaet og oppgir ingen interessekonflikter.

\section{Litteratur}

1. Moya A, Sutton R, Ammirati F et al. Guidelines for the diagnosis and management of syncope (version 2009). Eur Heart J 2009; 30: 2631-71.

2. Rosanio S, Schwarz ER, Ware DL et al. Syncope in adults: systematic review and proposal of a diagnostic and therapeutic algorithm. Int J Cardiol 2013; 162: 149-57.

3. Benvenuto LJ, Krakoff LR. Morbidity and mortality of orthostatic hypotension: implications for management of cardiovascular disease. Am J Hypertens 2011; 24: 135-44.

4. D'Ascenzo F, Biondi-Zoccai G, Reed MJ et al. Incidence, etiology and predictors of adverse outcomes in 43,315 patients presenting to the Emergency Department with syncope: an international meta-analysis. Int J Cardiol 2013; 167: 57-62.

5. Derose SF, Gabayan GZ, Chiu VY et al. Patterns and preexisting risk factors of 30-day mortality after a primary discharge diagnosis of syncope or near syncope. Acad Emerg Med 2012; 19: 488-96.

6. Forskrift om førerkort m.m. Vedlegg 1 - Helsekrav. Oslo: Vegdirektoratet, 2004.

7. Regler og veiledning for utfylling av helseattest for førerkort mv. - 2010. Oslo: Helsedirektoratet, 2011

8. Serrano LA, Hess EP, Bellolio MF, et al. Accuracy and quality of clinical decision rules for syncope in the emergency department: a systematic review and meta-analysis. Ann Emerg Med 2010; 56 : 362-73.e1.

9. Camm AJ, Kirchhof P, Lip GY et al. Guidelines for the management of atrial fibrillation: the Task Force for the Management of Atrial Fibrillation of the European Society of Cardiology (ESC). Eur Heart J 2010; 31: 2369-429

Mottatt 22.2. 2013, første revisjon innsendt 1.6. 2013, godkjent 4.7. 2013. Redaktør: Merete Kile Holtermann. 